\title{
VIRUS COMO INDUCTORES DE NEOPLASIAS CUTÁNEAS
}

\author{
Francisco Bravo Puccio ${ }^{1, a}$
}

\begin{abstract}
RESUMEN
El rol oncogénico de los virus en las neoplasias cutáneas es conocido por el hombre desde hace más de un siglo, cuando se atribuía el origen de la verruga vulgar al virus papiloma humano (VPH). En la actualidad, las neoplasias inducidas por virus pueden agruparse en tumores sólidos y procesos linfoproliferativos. Destacan entre los primeros el VPH, del cual ahora conocemos numerosos serotipos, cada uno vinculado a una neoplasia específica, el herpesvirus humano tipo 8 que produce el sarcoma de Kaposi y el poliomavirus vinculado al carcinoma de Merkel. Entre los procesos linfoproliferativos debemos mencionar al virus linfotrópico de células T humanas tipo 1 (HTLV-1) responsable de los linfomas de células $\mathrm{T}$, en los cuales el compromiso cutáneo es inespecífico, con un amplio espectro de presentaciones clínicas y, que por consiguiente, plantean un reto para el diagnóstico diferencial. En este grupo también se encuentra el virus Epstein Barr vinculado a los linfomas nasales de Células NK/T y a los linfomas tipo Hidroa, de reciente descripción. En esta era en la que lo genético y lo molecular priman en las investigaciones en cáncer, no podemos dejar de lado el concepto de neoplasia como resultado de la infección por un agente viral, lo que abre una nueva veta de posibilidades de tratamiento anticanceroso basado en medicamentos antivirales.
\end{abstract}

Palabras clave: Papillomaviridae; Poliomavirus; Carcinoma de células escamosas; Carcinoma de células de Merkel; Virus linfotrópico de células T humanas tipo 1; Linfoma extranodal de células NK-T (fuente: DeCS BIREME).

\section{VIRUSES AS AGENTS INDUCING CUTANEOUS NEOPLASMS}

\begin{abstract}
The oncogenic role of viruses in cutaneous neoplasms has been known by humankind for more than a century, when the origin of the common wart, or verruca vulgaris, was attributed to the human papilloma virus (HPV). Currently, virusinduced cutaneous neoplasms may be grouped into solid tumors and lymphoproliferative disorders. HPV, from which various serotypes are now known, each being linked to a specific neoplasm, the human herpes virus type 8 producing Kaposi sarcoma, and the Merkel cell polyomavirus, highlight among the first group. Regarding the lymphoproliferative disorders, we should mention the human T-lymphotropic virus type I (HTLV-1), which is responsible for the T-cell lymphomas, in which the cutaneous manifestations are non-specific and have a wide spectrum, thus posing a challenge for differential diagnosis. The Epstein Barr virus, linked to nasal lymphomas of NK/T-cells and Hydroa-like cutaneous lymphomas, is also part of this group. In an era in which the genetic and molecular aspects of cancer research prevail, we may not leave behind the concept of neoplasms as a result an infection with a viral agent, which opens a wide array of new possibilities for cancer treatment based on antiviral drugs.
\end{abstract}

Key words: Papillomaviridae; Polyomavirus; Carcinoma, squamous cell; Carcinoma, Merkel cell; Human T-lymphotropic virus 1; Lymphoma, extranodal NK-T-cell (source: MeSH NLM).

\section{INTRODUCCIÓN}

La capacidad oncogénica de algunas familias de virus no es un tema ajeno a la dermatología ${ }^{(1)}$. Las neoplasias cutáneas asociadas a virus pueden agruparse, de manera general, en tumores sólidos y procesos linfoproliferativos. Como parte de los tumores sólidos podemos encontrar entidades clínicas tales como los carcinomas epidermoides inducidos por el Virus Papiloma Humano (VPH) y el carcinoma de Merkel inducido por el poliomavirus. Por su parte, dentro de los procesos linfoproliferativos podemos mencionar los inducidos por el virus linfotrópico de células T humanas tipo 1 (HTLV-1) o aquellos inducidos por el virus de Epstein Barr. Cada una de estas entidades clínicas vinculadas a factores de riesgo distintos y, evidentemente, con sintomatología diversa. Es así que la presente revisión presenta algunas de las principales neoplasias inducidas por virus.

\footnotetext{
Facultad de Medicina “Alberto Hurtado", Universidad Peruana Cayetano Heredia. Lima, Perú.

Médico dermatólogo.

Recibido: 28-01-13 Aprobado: 06-03-13
}

Citar como: Bravo Puccio F. Virus como inductores de neoplasias cutáneas. Rev Peru Med Exp Salud Publica. 2013;30(1):79-84. 


\section{TUMORES SÓLIDOS RELACIONADOS A VIRUS}

\section{VIRUS PAPILOMA HUMANO}

Hace más de 100 años que se describió la asociación entre el VPH y una neoplasia benigna, como es la verruga vulgar. En un comienzo se supuso que existía solo un tipo de VPH y que la variación morfológica entre las lesiones era debido a las diferencias en el epitelio en los sitios del cuerpo en los cuales las lesiones se presentaban. Años más tarde, el rol oncogénico del VPH se hizo manifiesto cuando los tipos 16,18 , y posteriormente los tipos 31 y 45 , se asociaron al desarrollo de carcinoma de mucosas, en especial del carcinoma de cérvix ${ }^{(2)}$. En la práctica clínica se puede apreciar esta capacidad oncogénica en la piel de los pacientes aquejados por una rara genodermatosis conocida como epidermodisplasia verruciforme (EV), en los cuales se puede observar la inducción directa de neoplasias malignas, debido a que estos pacientes tienen una inusual tendencia a infectarse hasta con 20 diferentes tipos de VPH, desarrollando lesiones similares a verrugas planas en el tronco, la espalda y los brazos; curiosamente, solo los VPH tipo 5 y 8 son capaces de inducir el carcinoma en pacientes con EV, el curso de esta inducción se caracteriza por la progresión de verruga plana a carcinoma in situ y, finalmente, a neoplasia invasiva ${ }^{(3)}$. Otro ejemplo palpable de esta capacidad oncogénica es la ocasional ocurrencia de carcinoma epidermoide en lesiones que clínicamente correspondían inicialmente a verrugas periungeales ${ }^{(4)}$, así como en la enfermedad de Bowen del lecho ungeal ${ }^{(5)}$, que pueden adoptar clínicas tan variadas como eritroniquia estriada o melanoniquia estriada.

El VPH infecta solo las células epiteliales de la superficie de la piel y las membranas mucosas; cuando la lesión es en la piel del pene, se usa el nombre de eritroplasia de Queyrat, que es un carcinoma in situ cuya lesión es usualmente única, macular, eritematosa y de superficie erosionada; si la lesión es similar pero se presenta en piel no genital se le denomina enfermedad de Bowen. En ambos casos el VPH implicado es el tipo 16 y la progresión a carcinoma epidermoide invasivo es posible. Esta asociación entre VPH y carcinoma aplica, en realidad, a todo carcinoma epidermoide (pene, vagina, vulva, escroto y ano), se consideran grupos de alto riesgo a los hombres que tienen sexo con otros hombres y a las personas con serología positiva para $\mathrm{VIH}$, en quienes el desarrollo de carcinomas perianales tiene presentaciones inusuales, tales como las formas ulcerativas o fistulosas y que además está asociado a una alta mortalidad ${ }^{(3)}$.

Los carcinomas verrucosos son formas de carcinoma epidermoide de bajo grado, que cuando ocurren en la zona genital se asocian a infecciones de VPH de tipos 6 y 11, y cuando son extragenitales al tipo 16. El condiloma gigante de Buschke Lowestein no es otra cosa que un carcinoma verrugoso de piel genital, sea pene, vulva o ano. Como su nombre lo indica es de proporciones gigantescas, con una conducta biológica intermedia, capaz de causar mucha destrucción o invasión local, pero con un muy bajo potencial metastático. Cuando el carcinoma verrugoso ocurre en la planta del pie se le conoce como carcinoma cuniculatum, pudiendo presentarse como una tumoración exofítica ulcerada, la clínica también puede ser la de un proceso endofítico, invasivo, entre espacios interdigitales, resultando en la formación de fístulas con contenido queratínico, se caracteriza por una alta tasa de recurrencia.

La papulosis bowenoide (PB) es una manifestación inusual de la infección por VPH en los genitales externos masculinos y femeninos. Clínicamente la apariencia es de una erupción de pápulas pigmentadas múltiples que afecta la superficie genital. Lo llamativo de esta condición es que al examen histológico, estas pápulas presentan características histológicas de displasia y carcinoma in situ, algo que no guarda relación con su apariencia benigna. Se asocia al VPH tipo 16 y aunque la progresión a carcinoma invasivo es muy rara, los pacientes con PB requieren de un seguimiento continuo.

La infección de la mucosa oral por VPH se puede producir por contacto oro-genital, pero también se da en el contexto de una propensión genética en niños de ciertos grupos étnicos, al que se le conoce como hiperplasia epitelial focal o enfermedad de Heck (EH). Los VPH más comúnmente asociados a EH pertenecen a los tipos 13, 32 y 57. Cabe anotar, sin embargo, que antes que la progresión a carcinoma, la historia natural de la EH es hacia la resolución espontánea. No obstante, la progresión a carcinoma oral a partir de infección por VPH es posible, y de hecho está claramente descrita en otra condición de la enfermedad oral conocida como papilomatosis oral florida.

\section{HERPESVIRUS HUMANO 8: SARCOMA DE KAPOSI}

El sarcoma de Kaposi (SK) es otro ejemplo del rol de los virus en procesos dermatológicos tumorales sólidos. La descripción original fue hecha por Moritz Kaposi, dermatólogo de la escuela de Viena en el año 1875, en aquel entonces el SK era considerada una condición relativamente rara, con una alta predilección a ocurrir en varones de etnia judía, de origen mediterráneo. A pesar de ser considerado un sarcoma, se diferenciaba de otros tumores malignos de estirpe vascular, como el angiosarcoma, por su menor agresividad y su rara aunque particular ocurrencia en relación a grupos étnicos específicos y a situaciones de inmunodeficiencia. Es en los 
años ochenta, con el surgimiento de las formas epidémicas de SK observadas en Nueva York en pacientes varones jóvenes con conducta homosexual surge la idea de una posible etiología infecciosa del SK, probablemente viral, en el contexto de una gran inmunodeficiencia producida por otro virus hasta ese momento desconocido. De hecho, esta teoría de una posible etiología viral fue publicada en 1981 por Gotlieb y Ackerman en la Universidad de Nueva York, alertados por la mayor incidencia por ellos observada en un laboratorio de dermatopatología ${ }^{(6)}$. Para 1996, Chang y Moore logran el secuenciamiento de un DNA viral relacionado a herpesvirus de las lesiones de SK ${ }^{(7)}$. Hoy en día es aceptado que todas las formas clínicas de SK, sean clásicas, endémicas, relacionadas a inmunodeficiencia o a infección por $\mathrm{VIH}$, están relacionadas con diferentes serotipos del herpesvirus humano 8 (HHV 8) y demostrar la presencia de este virus, por métodos de inmunohistoqúimica, se considera indispensable para el diagnóstico histológico del SK.

Un hecho que no puede dejar de ser mencionado, se da luego de la ocurrencia de casos de SK en pacientes de origen andino con serología negativa para $\mathrm{VIH}$. A partir de estos casos, Mohanna et al. consideraron la posibilidad que el SK en la población peruana es una condición frecuente e independiente de la infección por VIH ${ }^{(8)}$; a ello se debe sumar el hecho que los registros oncológicos peruanos previos a los años de la epidemia de SIDA ya mostraban una incidencia relativamente alta de SK, en comparación con lo encontrado en otros países latinoamericanos; más llamativo aún era que la población afectada no era de origen europeo sino andino ${ }^{(9)}$. Además, las formas clínicas atípicas, tales como lesiones bilaterales, patrones zosteriformes o presentaciones que primariamente afectaban cabeza y cuello, usuales en el contexto de la infección por VIH pero raras en la forma clásica, no eran inusuales en pacientes autóctonos peruanos con serología negativa para VIH. Pequeños estudios epidemiológicos en bancos de sangre de donantes peruanos permiten afirmar que nuestra población tiene un porcentaje significativo de pacientes seropositivos para el HHV 8, lo que explica las observaciones clínicas previamente descritas ${ }^{(10)}$. Todo ello sugiere que el SK en pacientes con serología negativa para $\mathrm{VIH}$ no es una neoplasia que afectaba exclusivamente a grupos étnicos específicos de origen europeo, sino que además puede afectar a poblaciones andinas, y en particular a la peruana. Esto ha devenido en la formación de grupos de investigación peruanos dedicados a estudiar SK en nuestro medio.

\section{POLIOMAVIRUS}

La más reciente de las neoplasias sólidas ligadas a virus es el carcinoma de Merkel. El tumor fue descrito originalmente por Toker como carcinoma trabecular, y agrupado entre los tumores neuroendocrinos. Es un carcinoma cutáneo infrecuente, que usualmente afecta a pacientes mayores y que con frecuencia se asienta en cabeza, cuello o extremidades. Es un tumor agresivo y capaz de producir metástasis. En el año 2008 Feng et al. fueron los primeros en reportar una novedosa asociación entre el carcinoma de Merkel y un tipo de poliomavirus, que recibe hoy el nombre de poliomavirus asociado a carcinoma de Merkel y que de hecho está presente en el $80 \%$ de estas neoplasias ${ }^{(11)}$.

\section{PROCESOS LINFOPROLIFERATIVOS CUTÁNEOS RELACIONADOS A VIRUS}

\section{VIRUS LINFOTRÓPICO DE CELULAS T HUMANAS TIPO 1 (HTLV-1)}

Un capítulo aparte lo constituyen los procesos linfoproliferativos primarios cutáneos ligados a virus, y su frecuencia en la población peruana. En el mundo, la micosis fungoide (MF) es, de lejos, el linfoma cutáneo más prevalente, muy por encima de la incidencia observada para otros linfomas $\mathrm{T}$ y otros linfomas cutáneos de células B. En el Perú, la predominancia de la MF se mantiene por sobre todos los otros linfomas; sin embargo, son comunes en nuestra estadísticas las condiciones linfoproliferativas ligadas a un segundo agente infeccioso viral, el HTLV-1. Este retrovirus fue descrito inicialmente como causante de leucemias y linfomas de células T (LCT) en poblaciones caribeñas y asiáticas, posteriormente se le asoció a otras condiciones no neoplásicas como la paraparesia espástica tropical y más recientemente con la dermatitis infectiva. Múltiples estudios epidemiológicos han demostrado la presencia de población infectada por HTLV-1 en forma significativa en zonas de Brasil (especialmente en el estado de Bahía), Colombia y también en el Perú, donde muestra una especial predilección por la población altoandina, y, en menor medida, en otros países, como Argentina y Chile.

En el Perú el LCT es el segundo linfoma más frecuente, luego de la MF, representando un $20 \%$ de todos los linfomas cutáneos primarios ${ }^{(12)}$. La clínica de LCT se caracteriza por presentar (tanto en las formas leucemicas, linfomatosas, crónicas y latentes) frecuentemente un compromiso cutáneo inespecífico, en el cual se puede apreciar una gran variedad de lesiones clínicas, desde formas maculares indistinguibles de la MF clásica hasta lesiones papulares, nodulares y tumorales. Esa gran variabilidad clínica plantea un diagnóstico diferencial amplio dentro del cual se debe considerar los procesos inflamatorios (eritema elevatum diutinum), la sarcoidosis, procesos neoplásicos (como carcinomas y sarcomas), el linfoma de células T anaplásico, la 
papulosis linfomatoide y el linfoma de células B grandes tipo de las piernas. Las formas cutáneas puras de LCT son de especial interés, en ellos las formas maculares pueden ser indistinguible de los estadios maculares de MF. De allí que hoy, en el Perú, es una idea de consenso entre dermatólogos y oncólogos que en el estudio inicial de todo paciente con linfoma cutáneo, se debe evaluar la serología para HTLV-1 al momento del diagnóstico.

Otra reciente descripción en el espectro del LCT atañe a una nueva forma cutánea tumoral primaria, donde autores japoneses y brasileros ${ }^{(13,14)}$ han observado que, aunque la enfermedad se limite a piel, el pronóstico no es tan bueno, en contraposición al buen pronóstico siempre asignado a las formas cutáneas puras de tipo latente. Esta sería una nueva categoría adicional a las ya descritas por Shimoyama ${ }^{(15)}$.

\section{VIRUS EPSTEIN BARR}

La capacidad del virus de Epstein Barr (EBV) de inducir linfoma fue demostrada hace muchos años en pacientes africanos con Linfoma de Burkitt; esta asociación fue demostrada por el mismo Dr. Epstein en 1964. Desde entonces y hasta la fecha, el espectro de linfomas relacionados a EBV se ha ampliado. En el caso del Perú, el EBV ha sido implicado en dos entidades de características clínicas bien definidas, los linfomas nasales de células NK/T (LT/NK) y los linfomas tipo hidroa (LH).

Los linfoma nasales de células NK/T son neoplasias con una particular distribución geográfica, ocurren con relativa frecuencia en países asiáticos como Japón, Korea y China, mientras que en Latinoamérica se reporta con frecuencia en México y Perú (16); curiosamente, se considera un linfoma raro en Norteamérica y Europa. Las edades afectadas abarcan desde la niñez hasta la edad adulta, la enfermedad se inicia en la mucosa nasal y con frecuencia se extiende a la piel de la pirámide nasal pudiendo la clínica ser la de un edema difuso e infiltrante, o la de un proceso ulcerativo destructivo, en ambos casos afecta la zona centro-facial; estos signos clínicos acompañados de una lesión infiltrante o ulcerativa plantean con frecuencia el diagnóstico diferencial con enfermedades tropicales típicas de la región, como la leishmaniasis mucocutánea y la paracoccidiomicosis.

Desde el punto de vista histológico, los infiltrados linfomatosos pueden ser francamente atípicos, o a veces acompañarse de un cortejo de células inflamatorias, que pueden confundir al patólogo y hacen más difícil el diagnóstico. La angiocentricidad en los LT/ NK es un hallazgo común pero no debe ser considerada un requisito indispensable para el diagnóstico. El perfil inmuno-histoquímico muestra con frecuencia un patrón de diferenciación de células NK (natural killers) con marcadores de citotoxicidad, con un porcentaje menor de casos en los que las células neoplásicas no son NK sino variedades de células $\mathrm{T}$ (NK-T). Una particularidad de estos linfomas NK-T es la ausencia del rearreglo genético del receptor de células $T$, instrumento frecuentemente empleado para la determinación de monoclonalidad en procesos linfoproliferativos que atañen a linfocitos T. La presencia del EBV puede ser demostrada en la célula neoplásica proliferante por la técnica de hibridización in situ, usando sondas de tipo EBNA (antígenos nucleares del virus Epstein-Barr). El tratamiento de elección de estas lesiones cuando son localizadas es radioterapia, aunque es conocida su posibilidad de recidiva y mal pronóstico a largo plazo.

Capítulo aparte en los procesos linfoproliferativos relacionados a EBV es el recientemente descrito linfoma de células T de tipo hidroa ( $\mathrm{LH}$ ). La denominación hidroa se basa en la semejanza clínica con una afección de la dermatología clásica llamada hidroa vacciniforme, una fotodermatosis crónica, que se caracteriza por el desarrollo de lesiones ampollares en áreas faciales que acaban por producir cicatrices varioliformes, que fue descrita en los años noventa por dermatólogos mexicanos (17). Los pacientes eran niños, o adultos jóvenes, que presentaban un edema facial crónico recurrente, que se complicaba con frecuencia con formaciones tipo ampulares que dejaban cicatrices variceliforme; acompañado de hiperreactividad a picaduras de mosquitos y progresión, en algunos pocos pacientes, hacia el desarrollo de linfomas. Se interpretaba cómo un proceso inflamatorio, aunque con el potencial de evolucionar hacia un linfoma, que recibe el nombre de paniculitis y vasculitis edematosa y cicatrizal. En años posteriores se publicaron series de casos de pacientes mexicanos ${ }^{(18)}$, bolivianos ${ }^{(18)} \mathrm{y}$ peruanos ${ }^{(19,20)}$, tras lo cual se optó por denominar a este entidad como linfoma tipo hidroa (LH). Casos idénticos se publicaron de manera simultánea en la literatura japonesa y coreana estableciéndose ya en esos casos, una relación con el EBV ${ }^{21)}$. En analogía con lo descrito respecto a los LT/NK, deben resaltarse tres hechos importantes. Primero, la célula neoplásica es el linfocito T; segundo, el proceso claramente se asocia a infección activa por el EBV; y tercero, la distribución geográfica, que abarca países de Asia como Japón, Corea y China, así como países latinoamericanos como México, Bolivia y Perú. La relación con el EBV da pie para que diferentes investigadores empiecen a observar la evidencia de infección crónica por EBV en procesos tan diversos como hipersensibilidad a picaduras de mosquito e incluso en casos de hidroa vacciniforme clásica ${ }^{(22)}$. El concepto más actualizado de esta condición es que se trata de un conjunto de enfermedades asociadas a un estado crónico 
de infección por EBV, la enfermedad crónica activa por EBV, donde la clínica puede abarcar lo inflamatorio, una mezcla de inflamatorio y linfoproliferativo o un proceso francamente neoplásico, con todas las características de un linfoma. Así, el LH es parte de un espectro de entidades donde también estarían incluidos la hidroa vaccininiforme clásica, el edema facial unilateral persistente y la hiperreactividad a picaduras de mosquito y el muy severo síndrome hemofagocítico. Es importante resaltar la particularidad geográfica de la distribución de la enfermedad, casi exclusivamente países de Asia y Latinoamérica, lo que lleva a plantear la hipótesis del rol factor genético sumándose a la infección por EBV como desencadenante de estos particulares procesos linfoproliferativos.

Los desafíos actuales frente a estos pacientes radican en hacer el diagnóstico correcto del estadio, ya sea este inflamatorio o neoplásico. Los intentos iniciales de tratamientos quimioterápicos agresivos, bajo la asunción de que todos eran formas de linfoma, acabaron en una alta mortalidad, muchas veces por procesos infecciosos ligados a la inmunosupresión. Esto debe ponerse en contraste con el curso crónico que la enfermedad adopta en muchos pacientes, repitiendo lo observado por Ruiz Maldonado (17) en su serie original. Actualmente, los esfuerzos están dirigidos a establecer los criterios que definirían la enfermedad en sus diferentes estadios y al tratamiento adecuado (que dependerá del estadio al momento del diagnóstico). Aun cuando lo ideal sería tratar de disminuir la carga viral del EBV, no existe el antiviral específico capaz de arremeter contra este virus.

EI EBV no se limita a inducir enfermedad linfoproliferativa. Recientemente se ha descrito el rol de este virus en la etiología de múltiples tumores de musculo liso que ocurren en pacientes jóvenes con SIDA, en varias localizaciones del cuerpo ${ }^{(23)}$. El comportamiento de estos tumores no es siempre agresivo, aunque pueden llegar a ser muy sintomáticos dependiendo de su localización, en especial cuando afectan el sistema nervioso central. La evidencia de la infección por EBV se basa en la positividad de las pruebas de hibridación in situ, usando las sondas EBER (Epstein Barr-encoded RNA). Se considera que este es un fenómeno que solo se puede explicar en el contexto de la inmunosupresión inducida por el $\mathrm{VIH}$ en estos pacientes.

\section{CONCLUSIONES}

No se puede negar las interacciones existentes entre los virus y la piel, por el contrario, se debe tratar de ampliar el conocimiento en torno al rol oncogénico de algunos de estos virus. Este nuevo conocimiento no solo tendría implicancias en las teorías de la génesis de la neoplasia, sino además mostrarían que estos procesos son producto de complejas relaciones de equilibrio entre los virus y el sistema inmune. Los recientes descubrimientos acerca de la capacidad del poliomavirus de desarrollar carcinoma, nos alerta y hace pensar en los múltiples virus aún desconocidos para la ciencia moderna, que podrían estar implicados en el desarrollo de tumores cutáneos tanto benignos como malignos. A la luz de la evidencia no debemos dejar de lado el concepto de neoplasia como resultado de la interacción con un agente infeccioso, más específicamente con uno de tipo viral; ello abre una nueva veta de posibilidades de tratamiento anticanceroso basados en medicamentos antivirales.

Financiamiento: autofinanciado.

Conflictos de interés: el autor niega conflictos de interés.

\section{REFERENCIAS BIBLIOGRÁFICAS}

1. Bravo F. Virus y neoplasia en Latinoamerica. Med Cutan Iber Lat Am. 2010;38(1):1-3.

2. Satyaprakash A. Mansur C. Human Papillomavirus. In: Tyring SK, Yen Moore $\mathrm{A}$ and Lupi $\mathrm{O}$ (eds). Mucocutaneous Manifestations of Viral Diseases, 2ed, London: Informa Healthcare; 2010.

3. Riddel C, Rashid R, Thomas V. Ungual and periungual humanpapillomavirus-associated squamous cell carcinoma: a review. J Am Acad Dermatol. 2011;64(6):1147-53.

4. Grundmeier N, Hamm H, Weissbrich B, Lang SC, Bröcker EB, Kerstan A.
High-risk human papillomavirus infection in Bowen's disease of the nail unit: report of three cases and review of the literature. Dermatology. 2011;223(4):293-300.

5. Corti M, Villafañe MF, Marona E, Lewi D. Anal squamous carcinoma: a new AIDS-defining cancer? Case report and literature review. Rev Inst Med Trop Sao Paulo. 2012;54(6):345-8.

6. Gottlieb GJ, Ragaz A, Vogel JV, Friedman-Kien A, Rywlin AM, Weiner EA, et al. A preliminary communication on extensively disseminated Kaposi's sarcoma in young homo- sexual men. Am J Dermatopathol. 1981;3(2):111-4.

7. Moore PS, Gao SJ, Dominguez G, Cesarman E, Lungu O, Knowles DM, et al. Primary characterization of a herpesvirus agent associated with Kaposi's sarcomae. J Virol. 1996;70(1):549-58.

8. Mohanna S, Maco V, Gown A, Morales D, Bravo F, Gotuzzo E. Is classic Kaposi's sarcoma endemic in Peru?: report of a case in an indigenous patient. Am J Trop Med Hyg. 2006;75(2):324-6.

9. Mohanna S, Maco V, Bravo F, Gotuzzo E. Epidemiology and clinical characteristics of classic Kaposi's sarcoma, 
seroprevalence, and variants of human herpesvirus 8 in South America: a critical review of an old disease. Int J Infect Dis. 2005;9(5):239-50.

10. Mohanna S, Portillo JA, Carriquiry G, Vidal J, Ferrufino JC, Sanchez J, et al. Human herpesvirus- 8 in Peruvian blood donors: a population with hyperendemic disease? Clin Infect Dis. 2007;44(4):558-61.

11. Feng H, Shuda M, Chang Y, Moore PS. Clonal integration of a polyomavirus in human Merkel cell carcinoma. Science. 2008;319(5866):1096-100.

12. Beltrán $\mathrm{B}$, Morales $\mathrm{D}$, Quiñones $\mathrm{P}$, Hurtado de F, Riva L, Yabar A, et al. Linfomas cutáneos primarios: estudio retrospectivo clinicopatológico durante el periodo 1997 - 2004 en el Hospital Edgardo Rebagliati Martins, Essalud, Lima, Perú. Acta Med Peruana. 2008;25(2):81-4.

13. Yamaguchi $\mathrm{T}$, Ohshima K, Karube K, Tutiya T, Kawano R, Suefuji H, et al. Clinicopathological features of cutaneous lesions of adult T-cell leukaemia/lymphoma. Br J Dermatol. 2005;152(1):76-81.

14. Bittencourt AL, Barbosa HS, Vieira MD, Farré L. Adult T-cell leukemia/ lymphoma(ATL) presenting in the skin: clinical, histological and immunohistochemical features of 52 cases. Acta Oncol. 2009;48(4):598-604.
15. Shimoyama M. Diagnostic criteria and classification of clinical subtypes of adult T-cell leukaemia-lymphoma. A report from the Lymphoma Study Group (1984-87). Br J Haematol. 1991;79(3):428-37.

16. Barrionuevo C, Zaharia M, Martinez MT, Taxa L, Misad O, Moscol A, et al. Extranodal NK/T-cell lymphoma, nasal type: study of clinicopathologic and prognosis factors in aseries of 78 cases from Peru. Appl Immunohistochem Mol Morphol. 2007;15(1):38-44.

17. Ruiz-Maldonado R, Parrilla FM, Orozco-Covarrubias ML, Ridaura C, Tamayo Sanchez L, Duran McKinster C. Edematous, scarring vasculitic panniculitis: a new multisystemic disease with malignant potential. J Am Acad Dermatol. 1995;32(1):37-44.

18. Magaña M, Sangüeza P, Gil-Beristain J, Sánchez-Sosa S, Salgado A, Ramón $\mathrm{G}$, et al. Angiocentric cutaneous T-cell lymphoma of childhood (hydroa-like lymphoma): a distinctive type of cutaneous T-cell lymphoma. J Am Acad Dermatol. 1998;38(4):574-9.

19. Barrionuevo C, Anderson VM, Zevallos-Giampietri E, Zaharia M, Misad O, Bravo F, et al. Hydroa-like cutaneous Tcell lymphoma: a clinicopathologic and molecular genetic study of 16 pediatric cases from Peru. Appl Immunohistochem Mol Morphol. 2002;10(1):7-14.
20. Rodríguez-Pinilla SM, Barrionuevo C, Garcia J, Martínez MT, Pajares R, Montes-Moreno S, et al. EBV-associated cutaneous NK/T-cell lymphoma: review of a series of 14 cases from Peru in children and young adults. Am J Surg Pathol. 2010;34(12):1773-82.

21. Iwatsuki K, Ohtsuka M, Akiba H, Kaneko F. Atypical hydroa vacciniforme in childhood: from a smoldering stage to Epstein-Barr virus-associated lymphoid malignancy. J Am Acad Dermatol. 1999; 40(2 Pt 1):283-4.

22. Iwatsuki K, Satoh M, Yamamoto T, Oono T, Morizane S, Ohtsuka M, et al. Pathogenic link between hydroa vacciniforme and Epstein-Barr virusassociated hematologic disorders. Arch Dermatol. 2006;142(5):587-95.

23. Purgina B, Rao UN, Miettinen M, Pantanowitz L. AIDS-Related EBVAssociated Smooth Muscle Tumors: A Review of 64 Published Cases. Patho$\log$ Res Int. 2011; 2011:561548.

Correspondencia: Francisco Bravo Puccio. Dirección: Angamos 896, Miraflores, Lima 18, Perú.

Teléfono: (511) 446-6250

Correo electrónico:fbravopuccio@gmail.com

\section{Consulte la versión electrónica de la} Revista Peruana de Medicina Experimental y Salud Pública en www.pubmed.gov

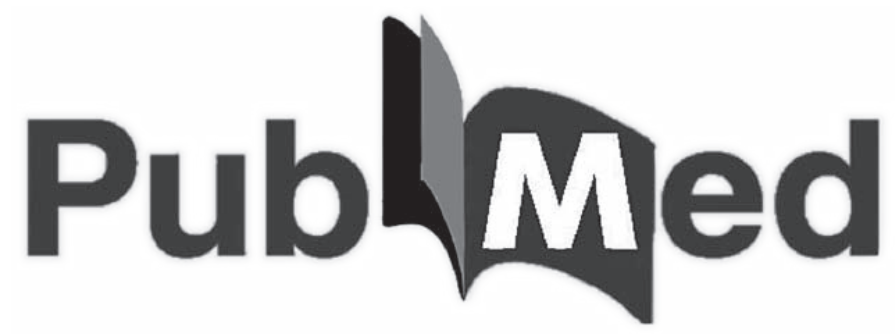

